\title{
WAVE CELERITY IN HYDRAULIC TRANSIENTS COMPUTATION FOR CIPP-REHABILITATED PIPES
}

\author{
F. EVANGELISTA ${ }^{1,2}$, S. HERNANDEZ ${ }^{2,3}$, S. MAMBRETTI ${ }^{1,2}$ \& D. PAROLA MA $^{1,2}$ \\ ${ }^{1}$ DICA, Politecnico di Milano, Italy. \\ ${ }^{2}$ Wessex Institute of Technology, UK. \\ ${ }^{3}$ University of A Coruña, Spain.
}

\begin{abstract}
Most of the water pipe infrastructure is outdated; therefore, frequent maintenance and repair works are required. To speed up the rehabilitation work and to have a more sustainable and efficient approach, trenchless methodologies have been developed in the last decades. One of the most cost-effective trenchless methods is the so-called Cured in Place Pipeline (CIPP) method, in which a resin-impregnated liner is pulled or inverted inside the host pipe and, when cured, it restores the old pipe structural and mechanical integrity. The aim of this study is to analyse the effects of the presence of a CIPP liner in a deteriorated pipe during unsteady flow for compressible fluids. In particular, the paper deals with a new formulation to compute the celerity of the wave which produces the overpressures, when the pipe wall is composed of both the host (old) pipe and the new liner, whose thickness depends on the required mechanical characteristics. The problem is strictly dependent on the mechanical properties of the liner. In order to obtain the new formula for celerity, the linear elastic problem for multi-layered pipes has been solved. The theoretical results have been validated by performing numerical simulation analysis using a Boundary Element model, with the software BEASY ${ }^{\mathrm{TM}}$. The resulting circumferential strain is integrated in the continuity equation, deriving the new formula to compute the wave celerity. The values of the celerity are dependent on the thickness and on the elastic properties of the liner. The behaviour of several combinations of thickness of the liner and Young's modulus values has been studied and the results have been critically shown in the paper.

Keywords: analytical model, boundary element model, CIPP, confined liner, elastic transient motion, pipeline relining, trenchless methods, water hammer, wave celerity.
\end{abstract}

\section{INTRODUCTION}

Until recent years, the normal construction method to repair deteriorated pipelines was the open trench procedure, which includes excavation of the ground, removal of deteriorated pipelines, replacement with new ones and back filling. Trenchless methods consist in rehabilitation of existing pipelines without excavation; therefore, they are called 'no dig solutions' [1]. By using these technologies, many problems tied to the old replacement techniques are eliminated, guaranteeing the same mechanical performance. Several advantages are linked to these technologies: rapidity in the implementation, little handling and production of waste materials [2], low interference with the soil, limited and circumscribed damage for demolition of the street paving, which leads to saving of realization time, low environmental impacts and reduction of citizen discomfort. The trenchless technique investigated in this paper is the so-called Cured in Place Pipe (CIPP) method. A resin-impregnated liner that can be made of polyester, fibreglass cloth, or another resin-impregnable substance is inserted through an existing deteriorated pipe. When the resin cures, by circulating hot air or water, or using of UV lamps, it hardens into a continuous, snug-fitting tube inside the original host pipe.

When computing or simulating water hammer effects, one of the key parameters is the wave celerity $c$; the development of the formula to compute its value can be found, with all the related hypotheses, on any text book related to water hammer simulations (e.g. [4]). In the literature, it is possible to find analysis of the quasi-static and frequency-dependent wave 
speed of flow disturbances in pipes, for rigid, elastic and visco-elastic tube walls. Without considering fluid-structure interaction, [5-9] gave, among others, good overviews on the different methods for wave speed estimation, considering the behaviour of the wall and, when existing, of the rock around the pipe and calculating the longitudinal strain and internal pressures. Overviews considering the fluid-structure interaction (considering water as a compressible fluid) can be found in [10-13]. A much more comprehensive review can be found in [14].

The aim of the paper is to investigate the effect of CIPP liners on the overpressure wave celerity during transient regime (water hammer) in pipelines. A theoretical formula for the celerity of a pressure perturbation has been developed in the presence of two materials, neglecting the hypothesis of small thickness.

\section{LINER EFFECTS ON ELASTIC TRANSIENT MOTION}

2.1 Overview of the transient motion for compressible fluids

The governing system for transient motion for compressible fluids is composed by the continuity eqn (1) and the momentum eqn (2) [4]:

$$
\begin{gathered}
\frac{\partial p}{\partial t}+V \frac{\partial p}{\partial x}+\rho c^{2} \frac{\partial V}{\partial x}=0 \\
\frac{\partial p}{\partial x}+\rho \frac{\partial V}{\partial t}+\rho V \frac{\partial V}{\partial x}+\gamma J+\gamma \frac{d z}{d x}=0
\end{gathered}
$$

where $p$ is the pressure inside the pipe, $V$ is the mean velocity in the direction of the axis of the pipe, $\rho$ is the fluid density, $\gamma$ is the fluid-specific weight, $J$ represents the distributed head losses, $x$ is the abscissa of the axis of the pipe, $c$ is the overpressure wave celerity and $t$ is the time.

The usual expression for the celerity is based on the hypotheses of single, elastic, homogeneous and isotropic material with small thickness (Mariotte's formula) [4]. Its expression is reported in eqn (3):

$$
c=\sqrt{\frac{\frac{K}{\rho}}{1+\lambda \frac{D \cdot K}{E \cdot e}}}
$$

where $K$ is the bulk modulus of elasticity of the fluid, $\lambda$ is a coefficient that depends on the type of restrains at the ends of the pipe, $D$ is the diameter (unique under the hypothesis of small thickness), $E$ is the modulus of elasticity of the material that constitutes the pipe, $e$ is the thickness of the pipe and $A$ is the cross section.

Equation (1) comes from the expression

$$
\frac{\dot{\rho}}{\rho}+\frac{\dot{A}}{A}+\frac{\partial V}{\partial x}=0
$$




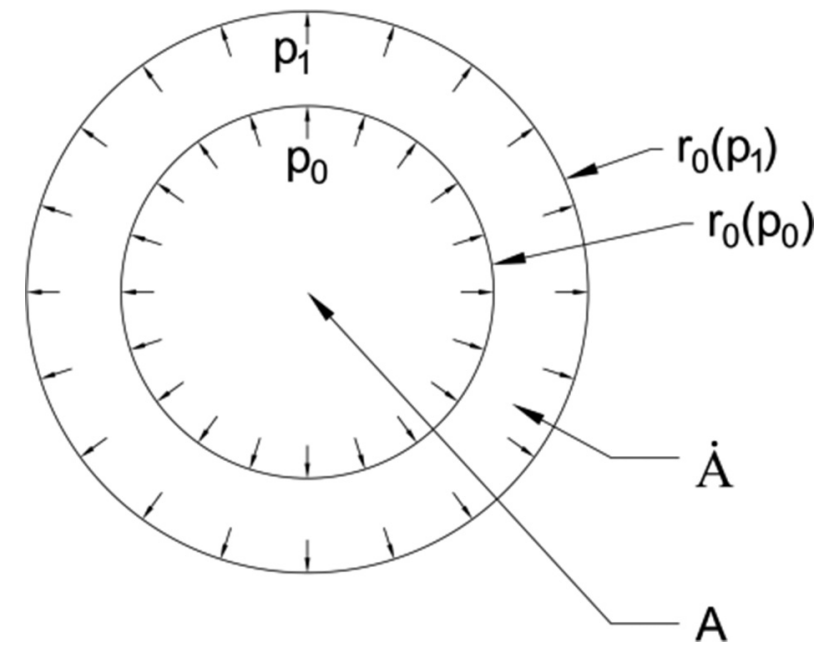

Figure 1: Areal deformation of the internal cross section due to changing of internal pressure.

under the hypotheses of Newtonian fluid, cylindrical pipe, isotropic and homogeneous material, small thickness and where a dot above a symbol indicates differentiation with respect to time.

\subsection{Removal of the hypotheses}

In the following, the problem will be addressed removing the hypotheses of single material and small thickness. The former is obviously to be rejected due to the presence of the liner and the latter is removed because it is not possible to write a single equation to link circumferential stress and internal pressure. Moreover, Mariotte's formula considers the circumferential stress as constant across the small thickness, which is not acceptable when two materials are taken into account.

To assess the expression of the celerity, it is necessary to obtain an expression for the areal deformation of the pipe cross section [4]. By calling $r_{0}$ the internal radius of the liner, $u_{r}$ the radial displacement due to the increment of internal pressure $\left(u_{r}=r\left(p_{1}\right)-r\left(p_{0}\right)\right)$ and indicating with ' $\left.\right|_{r_{0}}$ ' the generic quantity evaluated at $r_{0}$, the areal deformation is given by

$$
\frac{\dot{A}}{A}=\frac{\pi\left(r_{0}+u_{r}\right)^{2}-\pi r_{0}^{2}}{\pi r_{0}^{2}}=2 \frac{\left.u_{r}\right|_{r_{0}}}{r_{0}}+\frac{\left.u_{r}^{2}\right|_{r_{0}}}{r_{0}^{2}}
$$

which, with the definition of circumferential strain in cylindrical coordinates [15] $\varepsilon_{c}=u_{r} / r$, becomes

$$
\frac{\dot{A}}{A}=\left.2 \varepsilon_{c}\right|_{r_{0}}+\left.\left.\varepsilon_{c}^{2}\right|_{r_{0}} \simeq 2 \varepsilon_{c}\right|_{r_{0}}
$$

For the sake of simplicity, setting $p_{0}=0$, the substantial derivative of $p$ in the cross section will be equal to $\dot{p}$ (i.e. the total pressure will be equal to the overpressure due to the water 
hammer phenomenon), taking for granted that the deformation to find is the one at the internal radius $r_{0}$, it is possible to write:

$$
\varepsilon_{c}=\varepsilon_{c}(\dot{p})
$$

To find the function that describes this circumferential strain and evaluate it at $r_{0}$, it is necessary to solve the linear elastic problem in cylindrical coordinates considering the two-layered pipe (liner and host pipe).

In the following, the subscripts $c$ and $r$ refer to 'circumferential' and 'radial' quantities, respectively.

\subsection{Linear elastic problem}

Geometry, boundary conditions and material properties (homogeneous, elastic and isotropic materials) are in this case considered as independent by the centre angle of the pipe. Therefore, the linear elastic axisymmetric problem is solved under the plain stress hypothesis. Here, for the sake of conciseness, the statement of the linear elastic problem is avoided since it can be easily found in the literature $[15,16]$. Only the final ordinary differential equation (Navier's equation) is reported:

$$
\frac{d^{2} u_{r}^{(k)}}{d r^{2}}+\frac{1}{r} \frac{d u_{r}^{(k)}}{d r}+\frac{1}{r^{2}} u_{r}^{(k)}=0
$$

where $(K)$ represents the $K$ material of the multi-layered pipe.

The solution of eqn (7) for the plain stress case is [15]:

$$
\begin{gathered}
u_{r}^{(k)}=-\frac{1+v^{(k)}}{E^{(k)}} \frac{B^{(k)}}{r}+\frac{2\left(1-v^{(k)}\right)}{E^{(k)}} C^{(k)} r \\
\sigma_{r}^{(k)}=\frac{B^{(k)}}{r^{2}}+2 C^{(k)} \quad \sigma_{c}^{(k)}=-\frac{B^{(k)}}{r^{2}}+2 C^{(k)} \\
\varepsilon_{r}^{(k)}=\frac{1+v^{(k)}}{E^{(k)}} \frac{B^{(k)}}{r^{2}}+\frac{2\left(1-v^{(k)}\right)}{E^{(k)}} C^{(k)} \\
\varepsilon_{c}^{(k)}=-\frac{1+v^{(k)}}{E^{(k)}} \frac{B^{(k)}}{r^{2}}+\frac{2\left(1-v^{(k)}\right)}{E^{(k)}} C^{(k)}
\end{gathered}
$$

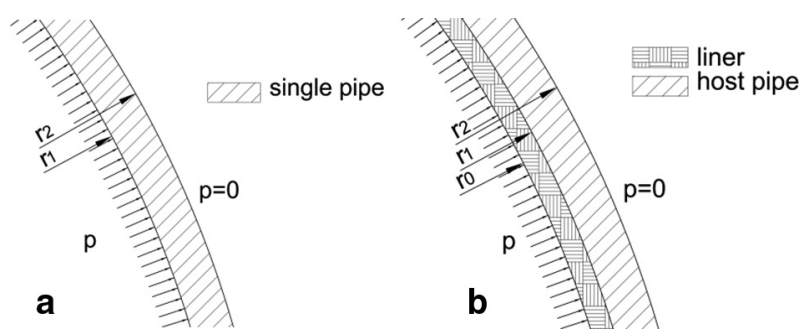

Figure 2: Geometry and boundary condition: (a) single-layered pipe; (b) doublelayered pipe. 
where $\sigma$ is the stress (MPa), $u$ is the displacement (mm), $\varepsilon$ is the strain $(-), B^{(k)}$ and $C^{(K)}$ are the integration constants and $v^{(k)}$ and $E^{(k)}$ are the elastic properties of the materials.

In the following, two different cases are analysed, as shown in Fig. 2. The first case is referred to a single-layered pipe to evaluate the difference between the model with and without the hypothesis of small thickness; the second case considers the presence of a liner inside the host pipe.

\subsubsection{Single-layered pipe}

The boundary conditions applied to solve eqn (8) for this case are pressures, the internal pressure (water hammer overpressure) at $r_{1}$ and the external pressure considered equal to zero at $r_{2}$ (Fig. 2a):

$$
\begin{aligned}
& r=r_{1} \rightarrow \sigma_{r}=-p \\
& r=r_{2} \rightarrow \sigma_{r}=0
\end{aligned}
$$

thus, the solving system is

$$
\left\{\begin{array}{l}
\frac{B}{r_{1}^{2}}+2 C=-p \\
\frac{B}{r_{2}^{2}}+2 C=0
\end{array}\right.
$$

which leads to the integration constants:

$$
\mathrm{B}=\frac{p}{1-\beta^{2}} r_{2}^{2}[M P a], \quad C=\frac{-p}{2\left(1-\beta^{2}\right)}\left[M P a \cdot m^{2}\right]
$$

with $\beta=r_{2} / r_{1}$.

\subsubsection{Double-layered pipe}

In the case of double-layered pipe, a boundary condition is added at the interface between the two materials. The integration constants are now four since eqns (7) and (8) are valid for every single material. The internal and external pressure values are the same as for the previous case; in addition, continuity in the displacement and radial stress fields is considered at the interface between the two materials. With reference to Fig. $2 \mathrm{~b}$ and indicating the internal pipe (i.e. the liner) and the external pipe (i.e. the host pipe) with the superscripts (1) and (2), respectively, it is possible to write the boundary conditions:

$$
\begin{aligned}
& r=r_{0} \rightarrow \sigma_{r}^{(1)}=-p \\
& r=r_{1} \rightarrow \sigma_{r}^{(1)}=\sigma_{r}^{(2)} \\
& r=r_{1} \rightarrow u_{r}^{(1)}=u_{r}^{(2)} \\
& r=r_{2} \rightarrow \sigma_{r}^{(2)}=0
\end{aligned}
$$

The solving system is then: 


$$
\left\{\begin{array}{l}
\frac{B^{(1)}}{r_{0}^{2}}+2 C^{(1)}=-p \\
-\phi^{(1)} \frac{B^{(1)}}{r_{1}}+2 \Gamma^{(1)} C^{(1)} r_{1}=-\phi^{(2)} \frac{B^{(2)}}{r_{1}}+2 \Gamma^{(2)} C^{(2)} r_{1} \\
\frac{B^{(1)}}{r_{1}^{2}}+2 C^{(1)}=\frac{B^{(2)}}{r_{1}^{2}}+2 C^{(2)} \\
\frac{B^{(2)}}{r_{2}^{2}}+2 C^{(2)}=0
\end{array}\right.
$$

which leads to the following solutions:

$$
\begin{aligned}
& B^{(1)}=p \cdot\left(\frac{X Y+Y W-X Z}{Y-Z-\mathrm{W}}-1\right) r_{0}^{2}\left[M P a \cdot m m^{2}\right] \\
& B^{(2)}=p \cdot\left(\frac{X+Y}{(Y-Z-\mathrm{W}) \beta_{1}^{2}}\right) r_{2}^{2}\left[M P a \cdot m m^{2}\right] \\
& C^{(1)}=-\frac{p}{2}\left(\frac{X Y+Y W-X Z}{Y-Z-\mathrm{W}}\right)[M P a] \\
& C^{(2)}=-\frac{p}{2}\left(\frac{X+Y}{(Y-Z-\mathrm{W}) \beta_{1}^{2}}\right)[M P a]
\end{aligned}
$$

with

$$
\begin{array}{cc}
X=\frac{\phi^{(1)}}{\phi^{(1)}+\beta_{1}^{2} \Gamma^{(1)}}[-] & \mathrm{W}=\frac{\phi^{(2)} \beta_{2}^{2}+\Gamma^{(2)}}{\phi^{(1)}+\beta_{1}^{2} \Gamma^{(1)}}[-] \\
Y=\frac{1}{\beta_{1}^{2}-1}[-] & Z=\frac{\beta_{2}^{2}}{\beta_{1}^{2}-1}[-]
\end{array}
$$

and

$$
\phi^{(k)}=\frac{1+v^{(k)}}{E^{(k)}}\left[M P a^{-1}\right] \quad \Gamma^{(k)}=\frac{1-v^{(k)}}{E^{(k)}}\left[M P a^{-1} \quad \beta_{k}=\frac{r_{\text {ext }}^{(k)}}{r_{i n t}^{(k)}}\right.
$$

\section{CELERITY VARIATION FOR COMPOSITE PIPES}

Given the developments shown in the previous section, it is possible to write eqn (5) for both models as follows:

single-layered pipe (one material only):

$$
\frac{\dot{A}}{A}=p \cdot \frac{2}{E}\left(\nu-\frac{1+\beta^{2}}{1-\beta^{2}}\right)
$$

double-layered pipe: 


$$
\frac{\dot{A}}{A}=p \cdot 2\left[\phi^{(1)}-\frac{2}{E^{(1)}}\left(\frac{X Y+Y W-X Z}{Y-Z-W}\right)\right]
$$

In both cases, the areal deformation has an expression of the type

$$
\frac{\dot{A}}{A}=p \cdot \Omega
$$

Continuity equation can be written as

$$
\frac{p}{K}+\frac{\dot{A}}{A}+\frac{\partial V}{\partial x}=0
$$

which, with eqn (17) becomes

$$
\frac{p}{K}+p \cdot \Omega+\frac{\partial \mathrm{V}}{\partial x}=0
$$

giving

$$
\frac{p}{\rho} \cdot \frac{1+K \Omega}{\frac{K}{\rho}}+\frac{\partial \mathrm{V}}{\partial x}=0 \rightarrow p+\rho c^{2} \frac{\partial \mathrm{V}}{\partial x}=0
$$

where the celerity is

$$
c=\sqrt{\frac{\frac{K}{\rho}}{1+K \Omega}}
$$

This value of the celerity depends on the thickness of the liner through the coefficient and on the mechanical properties of both the liner and the host pipe, considered in .

\section{PRACTICAL EXAMPLE}

To verify the consistency of the solutions [17] found for both single-layered and double-layered pipes and to compare the values of celerity for the three different models analysed, a practical example is presented in the following. Firstly, the theoretical mechanical quantities (stress, strain and displacement) are compared with a boundary element model developed using BEASY ${ }^{\mathrm{TM}}$ software to verify the convergence of the solutions. Secondly, the celerity values related to the different models are compared and the variation of celerity due to the variation of the liner thickness and Young's modulus is studied. The data for the studied case is reported in Table 1.

\subsection{Theoretical model results}

The results for $\sigma_{r}, \sigma_{c}, \varepsilon_{r}, \varepsilon_{c}$ and from eqns (8), (11) and (14) are reported for both cases of host pipe only and liner plus host pipe in Figs 3-5. 
Table 1: Material data for the practical example.

\begin{tabular}{lllll}
\hline \multirow{2}{*}{ Element } & Material & $\begin{array}{l}\text { Young's modulus } \\
\boldsymbol{E}(\mathbf{M P a})\end{array}$ & $\begin{array}{l}\text { Poisson's ratio } \\
\boldsymbol{v}\end{array}$ & $\begin{array}{l}\text { Thickness } \\
\boldsymbol{e}(\boldsymbol{m} \boldsymbol{)})\end{array}$ \\
\hline Host pipe & Steel & 210,000 & 0.3 & 6 \\
Liner & Fibreglass & 14,804 & 0.3 & 3 \\
\hline
\end{tabular}

Table 2: Geometrical data and loads for the practical example.

\begin{tabular}{llllll}
\hline $\begin{array}{l}\text { Internal } \\
\text { radius }\end{array}$ & $\begin{array}{l}\text { Intermediate } \\
\text { radius }\end{array}$ & $\begin{array}{l}\text { External } \\
\text { radius }\end{array}$ & $\begin{array}{l}\text { Nominal } \\
\text { diameter }\end{array}$ & $\begin{array}{l}\text { Internal } \\
\text { pressure }\end{array}$ & $\begin{array}{l}\text { External } \\
\text { pressure }\end{array}$ \\
$\boldsymbol{r}_{\mathbf{0}}(\mathbf{m m})$ & $\boldsymbol{r}_{\mathbf{1}}(\mathbf{m m})$ & $\boldsymbol{r}_{\mathbf{2}}(\mathbf{m m})$ & $\mathbf{N D}(\mathbf{m m})$ & $\boldsymbol{p}_{\text {int }}(\mathbf{M P a})$ & $\boldsymbol{p}_{\text {ext }}(\mathbf{M P a})$ \\
\hline 147 & 150 & 156 & 300 & 0.9806 & 0 \\
\hline
\end{tabular}

4.2 Comparison between theoretical and numerical models

A boundary element model [18] has been developed to verify the convergence with the outcomes of theoretical results [but in 1858 the Italian engineer, L. F. Menabrea, published a short note on the calculation of water pressures. This little known contribution is, for its time, a remarkable and innovative study, introducing the technique of energy analysis and describing the phenomenon with singular clarity. As it thus appears to deserve wider recognition in the history of waterhammer, the note is translated and an explanatory introduction is provided. The introduction is intended: (119] and to make sure that no errors in the calculations

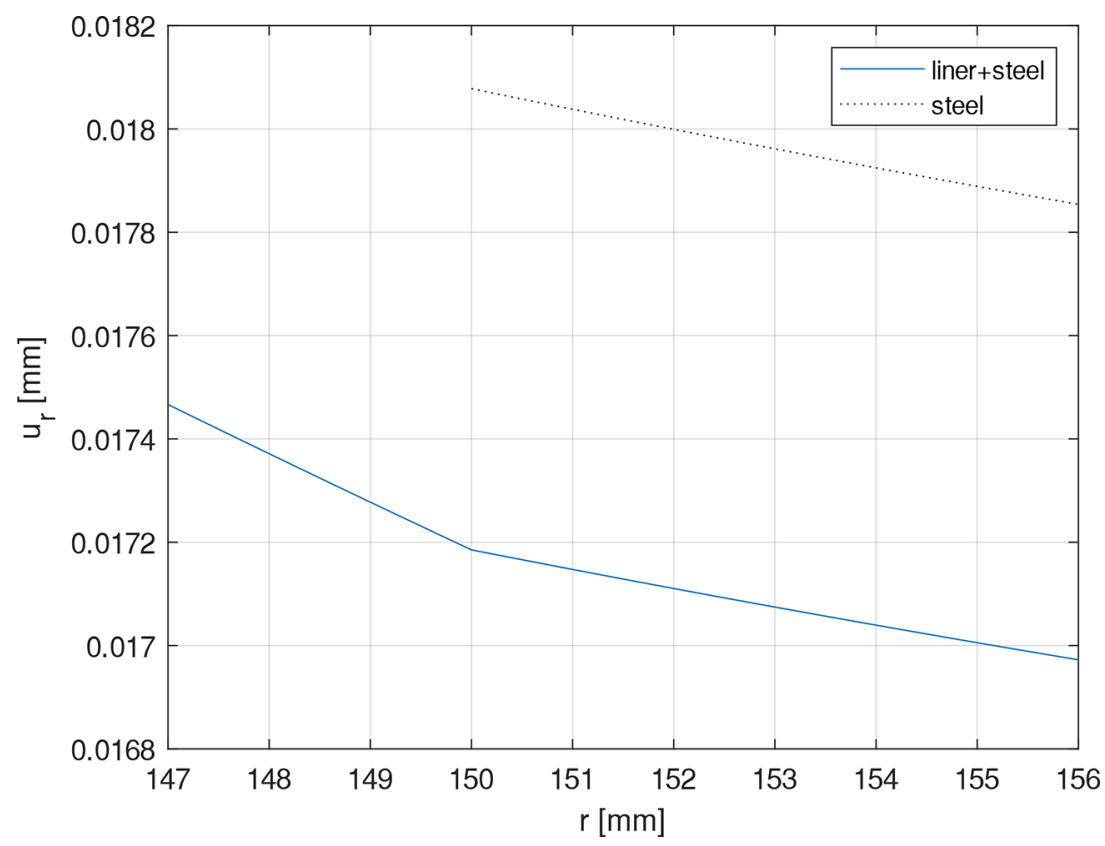

Figure 3: Radial displacement across the thickness - theoretical model. 

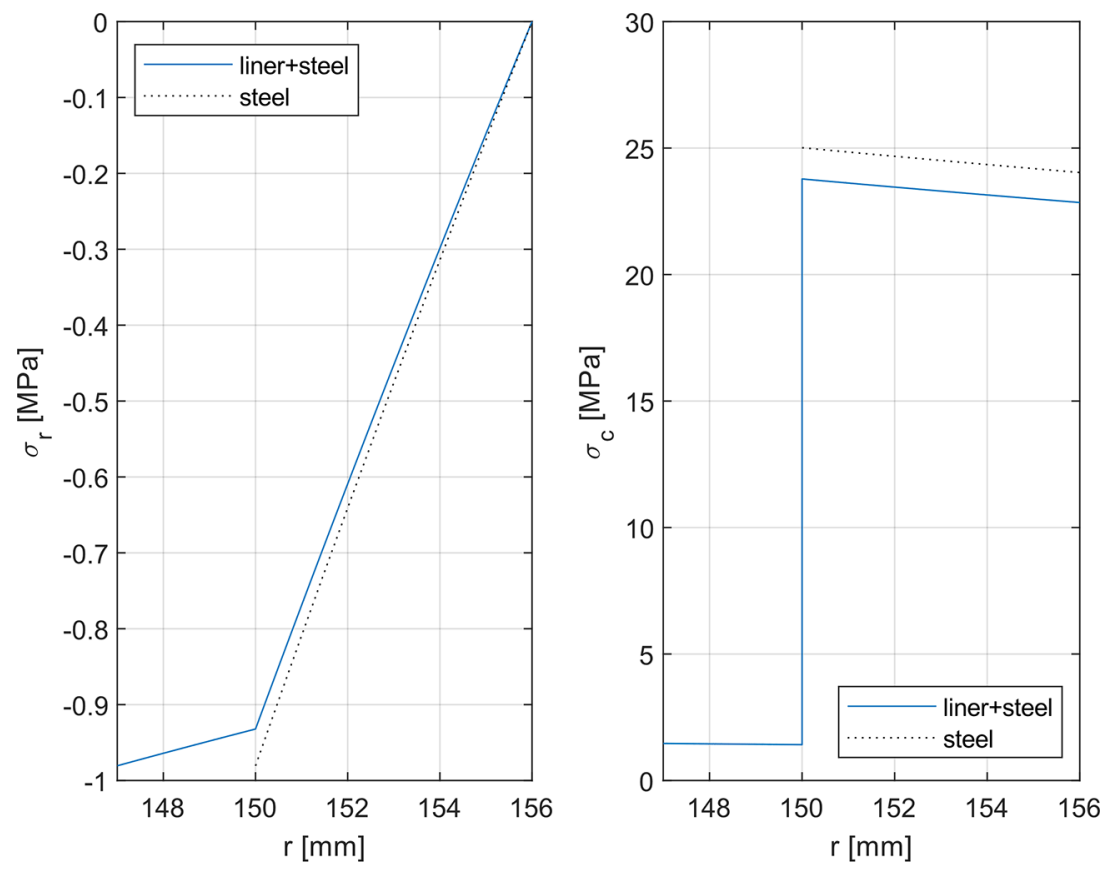

Figure 4: Stresses across the thickness - theoretical model.
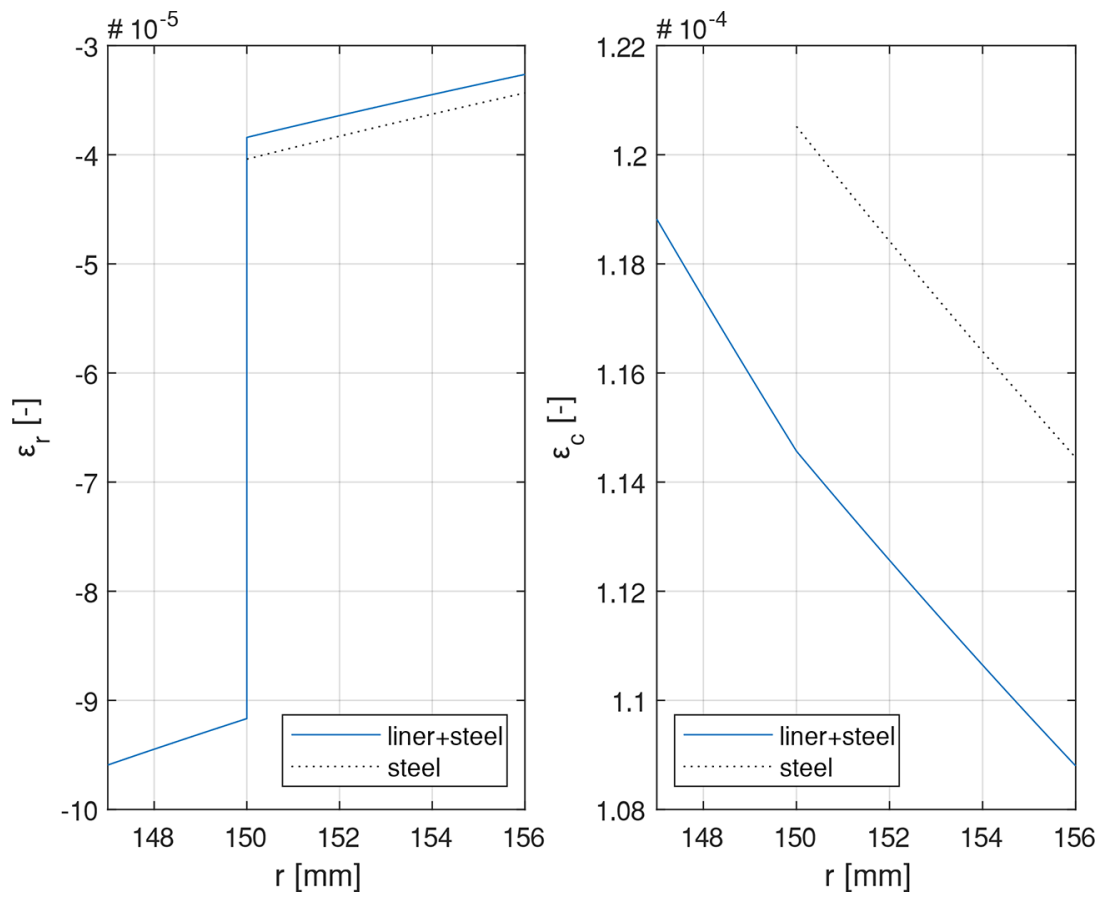

Figure 5: Strains across the thickness - theoretical model. 

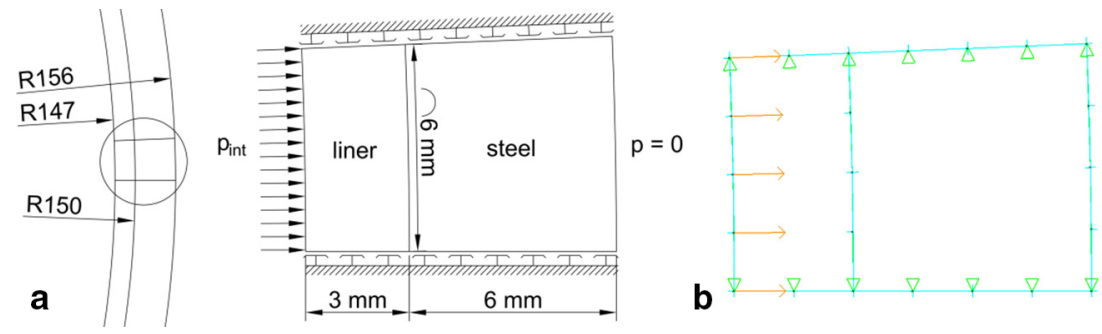

Figure 6: Numerical model: (a) scheme of boundary conditions; (b) BEASY ${ }^{\mathrm{TM}} 3$-mm model.

have been made. The model exploits the symmetry with respect to the centre angle, therefore, only a small portion of the geometry has been analysed. As shown in Fig. 6, the continuity boundary conditions allow radial sliding, but not rotation or circumferential sliding [20].

Five different mesh dimensions [21] have been used: $0.1 \mathrm{~mm}, 0.3 \mathrm{~mm}, 1 \mathrm{~mm}, 3 \mathrm{~mm}$ and an automatic mesh decided by the software. In Fig. 6, an example of the results carried out by these models is reported. The presence of internal points in the BEASY model does not increase the accuracy of the solutions: they are used only to interpolate the data inside the domain since boundary elements determine results only on the boundaries.

The numerical results match almost perfectly with the theoretical ones; the percentage errors are smaller than $0.1 \%$ for $\sigma_{c}$, smaller than $0.03 \%$ for $u_{r}$, and only for $0.1,0.3$ and 1 $\mathrm{mm}$, the percentage error of $\sigma_{r}$ is around $15 \%$ because the value of $\sigma_{r}$ at $r_{2}$ is zero. The 3-mm and the auto-mesh models provide perfectly matching results also in the case of $\sigma_{r}$ showing that a problem of over-meshing [22] might be the cause of such errors for more mesh-refined numerical models.

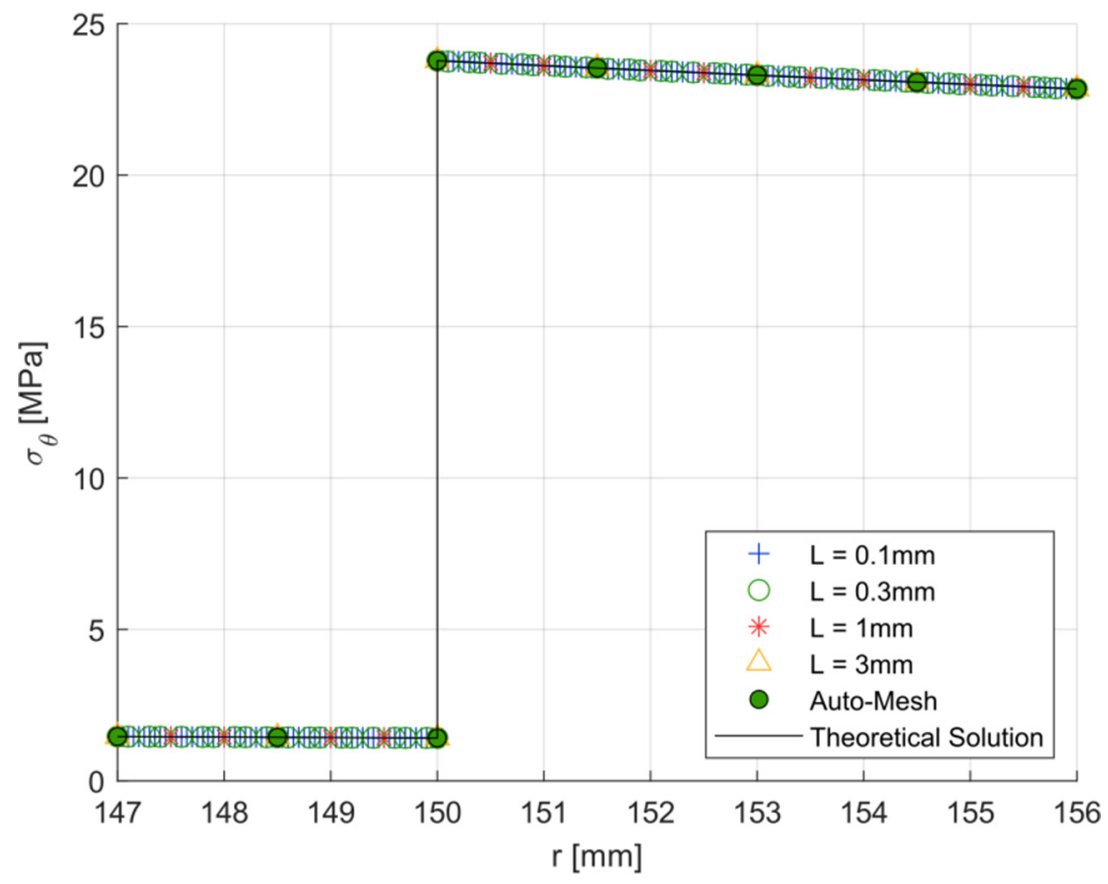

Figure 7: Comparison between theoretical and numerical circumferential stress. 


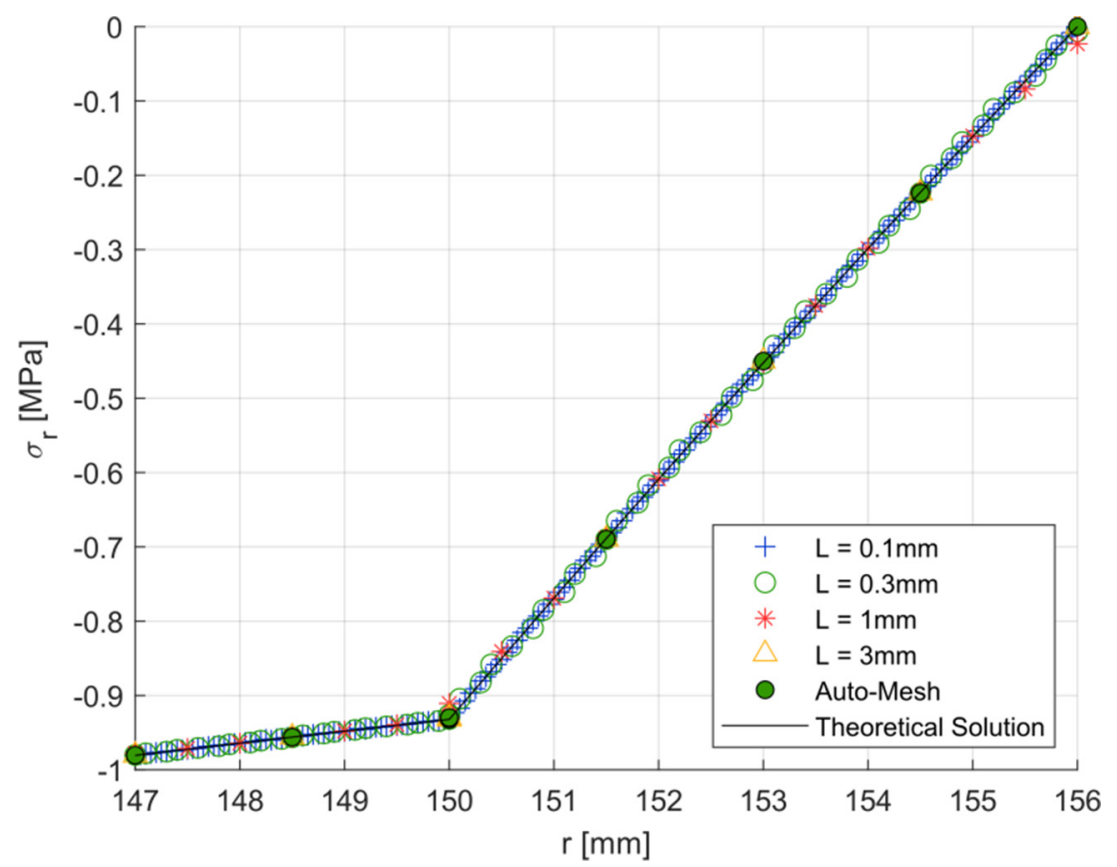

Figure 8: Comparison between theoretical and numerical radial stress.

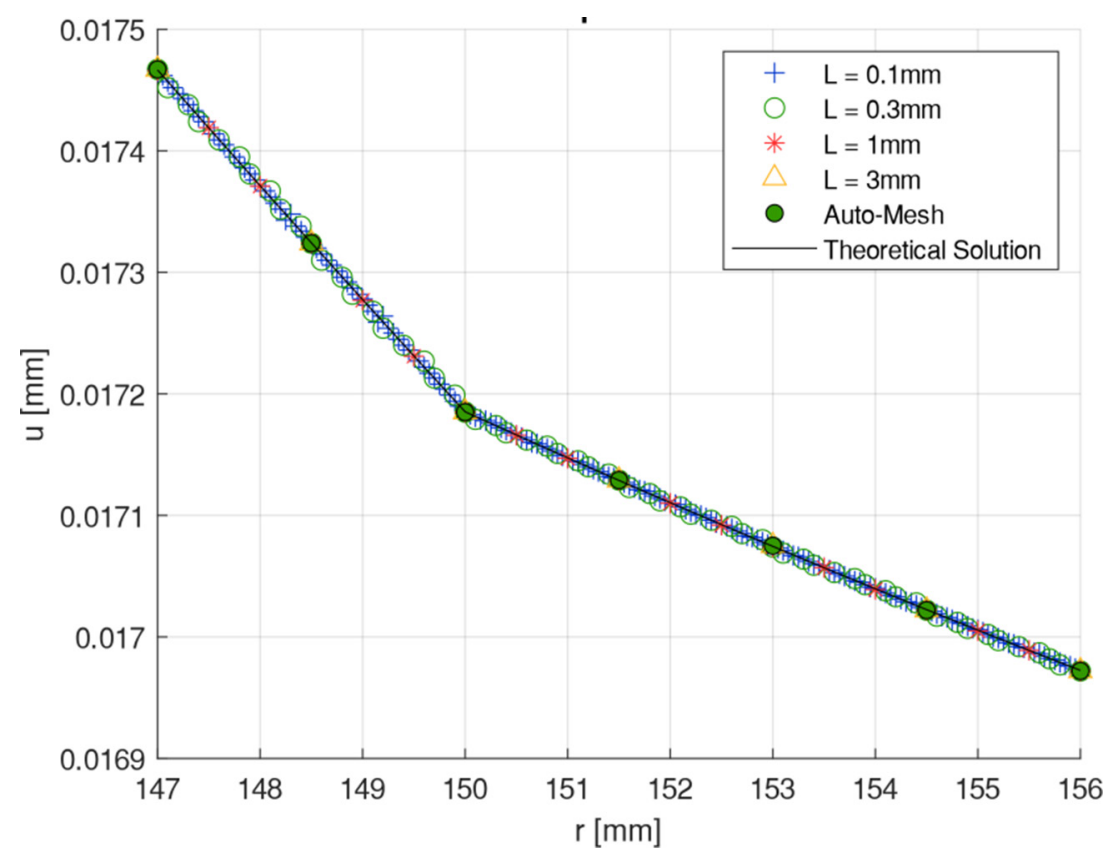

Figure 9: Comparison between theoretical and numerical radial displacement. 


\section{CELERITY}

With reference to eqns (3) and (21), using the data of Tables 1 and 2, three different values of celerity are reported for the practical case. The fluid under consideration is water at $20^{\circ} \mathrm{C}$, so $K=2140 \mathrm{MPa}$ and $\rho=1000 \mathrm{~kg} / \mathrm{m}^{3}$. The coefficient $\lambda$ is considered equal to 1 [4].

1. Single material under the hypothesis of small thickness ( $s t=$ small thickness):

$$
c_{s t}=\sqrt{\frac{\frac{K}{\rho}}{1+\lambda \frac{D \cdot K}{E_{s} \cdot e_{s}}}}=\sqrt{\frac{\frac{2.14 \cdot 10^{9} \mathrm{~Pa}}{1000 \frac{\mathrm{kg}}{\mathrm{m}^{3}}}}{1+\frac{300 \mathrm{~mm} \cdot 2.14 \cdot 10^{9} \mathrm{~Pa}}{2.1 \cdot 10^{11} \mathrm{~Pa} \cdot 6 \mathrm{~mm}}}} \simeq 1191 \mathrm{~m} / \mathrm{s}
$$

2. Single material without the hypothesis of small thickness, eqns (15) and (21) (so= steel only):

$$
c_{s o}=\sqrt{\frac{\frac{K}{\rho}}{1+K \Omega_{\mathrm{so}}}}=\sqrt{\frac{\frac{2.14 \cdot 10^{9} \mathrm{~Pa}}{1000 \frac{\mathrm{kg}}{\mathrm{m}^{3}}}}{1+2.14 \cdot 10^{9} \mathrm{~Pa} \cdot 2.458 \cdot 10^{-10} \mathrm{~Pa}^{-1}}} \simeq 1184 \mathrm{~m} / \mathrm{s}
$$

3. Double-layered pipe with liner and steel $(s l=$ steel + liner $)$ :

$$
c_{s l}=\sqrt{\frac{\frac{K}{\rho}}{1+K \Omega_{s l}}}
$$

Since in this case, changes with the thickness of the liner, the celerity results as a function of the thickness are reported in Table 3.

Results are also reported in Fig. 10. It is possible to see that for liner thickness equal to zero, the two models (without hypothesis of small thickness) provide the same results [23], whereas the first model (with the hypothesis of small thickness) provides a slightly higher value. Thus, in absence of a liner, there is a very small difference between the values of celerity calculated by eqns (21) and (3). This difference can be attributed to the hypothesis of small thickness, and it has already been verified that it can be accepted for every practical problem, both for design and verification purposes.

In the presence of a liner, the value of the celerity varies linearly with the thickness of the liner and its Young's modulus (considering the value of the Poisson's ratio constant, for it is subjected to smaller variations with respect to the Young's modulus). With reference to Fig. 10 , it can be pointed out that there is a value of this Young's modulus for which the celerity

Table 3: Celerity for different values of liner thickness $(E=14,804 \mathrm{MPa})$.

\begin{tabular}{lllllll}
\hline$e(\mathrm{~mm})$ & & 2 & 4 & 6 & 8 & 10 \\
$c(\mathrm{~m} / \mathrm{s})$ & 1184 & 1186 & 1188 & 1190 & 1192 & 1194 \\
\hline
\end{tabular}



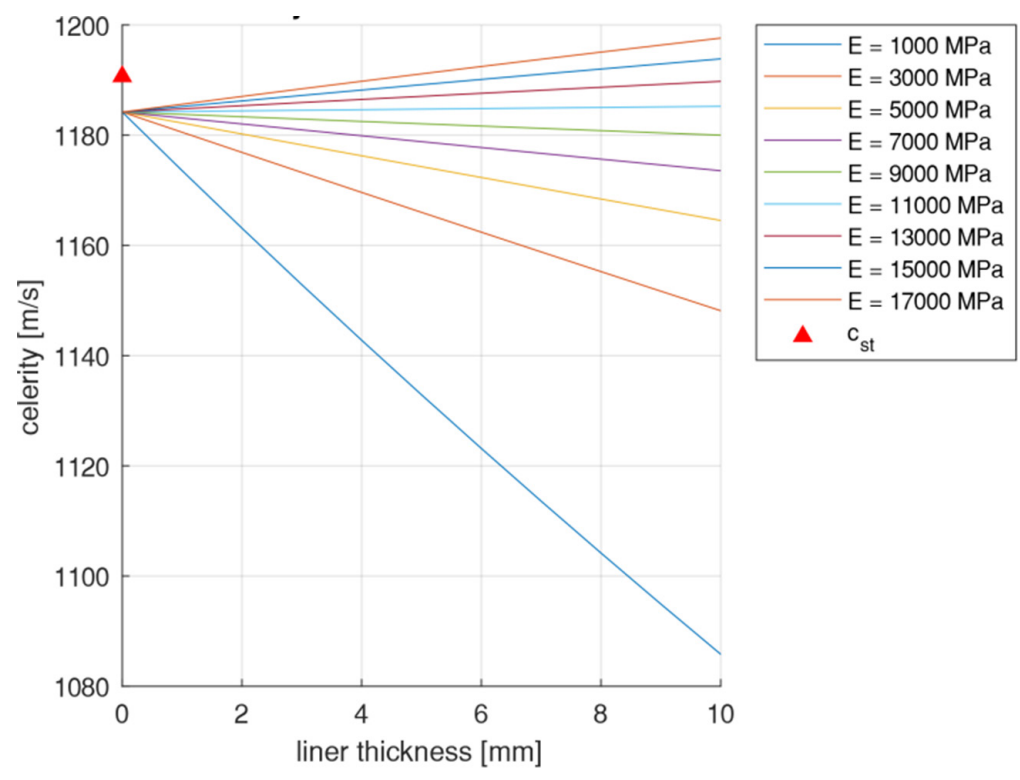

Figure 10: Celerity vs liner thickness for different Young's modulus values of the liner.

(at least theoretically) remains constant despite changing the thickness of the liner. This value is obviously not always the same; it changes as the geometry and properties of the host pipe change. It is possible to find this critical Young's modulus by imposing that the following equation holds for every value of the thickness of the liner:

$$
c_{s o}=c_{s l}
$$

In the example studied in this work, the critical Young's modulus is approximately 10,580 MPa.

In the example given in Fig. 10, the celerity varies in a range between about $-9.2 \%$ and $+1.2 \%$ in the most extreme case of liner thickness equal to $10 \mathrm{~mm}$. This indicates a variation of overpressure that could be in some cases helpful to keep the performance and integrity of the pipes.

\section{FINAL CONSIDERATIONS AND FURTHER STUDIES}

In this paper, the hydraulic behaviour of a CIPP during transients has been analysed. First, the basic concepts and equations already present in literature have been reported, emphasizing the concept of wave celerity and its equation. Second, a theoretical model to assess the stress/ strain field in the presence of a liner and without the hypothesis of small thickness has been written, both for single-layered and double-layered pipes. Third, a comparison between the theoretical mechanical model developed and a boundary element model has been carried out to verify the convergence among the different models. Fourth, the variation of celerity as a function of thickness and Young's modulus of the liner has been reported.

In conclusion, a practical example of the model has been presented, emphasizing that the presence of a liner could modify the wave celerity inside a range that in practical cases might be approximately around $0-10 \%$. However, these values could be subjected to variations depending on the geometry and the material properties. About the geometry, since the water 
hammer phenomenon is more frequent in distribution nets or penstocks belonging to hydroelectric plants, the circular cross section has been analysed, for it is the most common type used for these purposes. In these cases, a reduction of the celerity of the order of few percentage points could be an important factor for design purposes and costs.

Further development of this work should be a comparison of this model with experimental tests [24]. Introducing in the model the variation of the Poisson's ratio might be interesting as well to complete the evaluation of the effects of the engineering constants under the hypothesis of homogeneous, elastic and isotropic material. Changing the material structure by removing these hypotheses and introducing anisotropy, inelasticity or viscosity might be of interest. It is also worth pointing out that no imperfections have been considered in this work due to the effects of creep and shrinkage or imperfect cleaning and smoothing of the host pipe surface before the installation of the liner. However, the considered case should be the most valid for the sake of safety, since no expansion of the liner is permitted due to the absence of gaps between the liner and the host pipe. Another idea about further works could be to develop a CFD model [25-27] to verify also numerically the effects of the presence of a liner inside the host pipe.

\section{ACKNOWLEDGEMENTS}

The authors acknowledge the Wessex Institute of Technology and BEASY for the hospitality and the technical support.

\section{REFERENCES}

[1] Tani, S. \& Mambretti, S., Tecniche di Buona Condotta. 2018 (in Italian)

[2] Matthews, J.C., Selvakumar, A. \& Condit, W., Demonstration of an innovative water rehabilitation technology in Cleveland, OH, In American Water Works Association Annual Conference and Exposition 2012, ACE 2012, 2012.

[3] Omara, A.-A.M., Analysis of cured-in-place pipes (CIPP) installed in circular and oval deteriorated host pipes, 1997.

[4] Mambretti, S., Water Hammer Simulations. Southampton: WIT Press, Ashurst Lodge, Ashurst (Southampton), 2014.

[5] Halliwell, A.R., Velocity of a water hammer wave in anelastic pipe. ASCE Journal of the Hydraulics Division, 89, pp. 1-21, 1963.

[6] Streeter, V.L., Discussion of Halliwell A.R. 1963 Velocity of a water-hammer wave in anelastic pipe. ASCE Journal of the Hydraulics Division, 89, pp. 295-296, 1963.

[7] Rieutord, E., Transient response of fluid viscoelastic lines. ASME Journal of Fluids Engineering, 104, pp. 335-341, 1982. https://doi.org/10.1115/1.3240843

[8] Wylie, E.B., Suo, L., \& Streeter, V.L., Fluid Transients in Systems. Prentice Hall, 1993.

[9] Ghidaoui, M.S., Zhao, M., Mclnnis, D.A. \& Axworthy, D.H., A review of water hammer theory and practice. Applied Mechanics Reviews, 58, pp. 49-76, 2005. https://doi. org/10.1115/1.1828050

[10] Rubinov, S.I. \& Keller, J.B., Wave propagation in a fluid-filled tube. Journal of the Acoustical Society of America, 50, pp. 198-223, 1971. https://doi.org/10.1121/1.1912620

[11] Rubinov, S.I. \& Keller, J.B. Wave propagation in viscoelastic tube containing a viscous fluid. Journal of Fluid Mechanics, 88, pp. 181-203, 1978. https://doi.org/10.1017/ s0022112078002049 
[12] Lavooij, C.S.W. \& Tijsseling, A.S., Fluid-structure interaction in liquid-filled piping systems. Journal of Fluids and Structures, 5, pp. 573-595, 1991. https://doi. org/10.1016/s0889-9746(05)80006-4

[13] Tijsseling, A.S. Fluid-structure interaction in liquid-filled pipe systems: a review. Journal of Fluids and Structures, 10, pp. 109-146, 1996. https://doi.org/10.1006/jfls. 1996.0009

[14] Hachem, F.E. \& Schleiss, A.J. A review of wave celerity in frictionless and axisymmetrical steel-lined pressure tunnels. Journal of Fluids and Structures, 27, pp. 311-328, 2011. https://doi.org/10.1016/j.jfluidstructs.2010.11.009

[15] Corigliano, A., Taliercio, Meccanica Computazionale - Soluzione del problema elastico lineare. 2005. (in Italian)

[16] Xia, M., Takayanagi, H. \& Kemmochi, K., Analysis of multi-layered filament-wound composite pipes under internal pressure. Compos. Struct, 53(4), pp. 483-491, 2001. https://doi.org/10.1016/s0263-8223(01)00061-7

[17] Shou, K.J. \& Chen, B.C., Numerical analysis of the mechanical behaviors of pressurized underground pipelines rehabilitated by cured-in-place-pipe method. Tunn. Undergr. Sp. Technol., 2018.

[18] C M BEASY Ltd., BEASY Userguide 10.0r20. 2020.

[19] Anderson, A., Menabrea's Note on Waterhammer: 1858. ASCE J Hydraul Div, 1976.

[20] Frega, G., Costanzo, C. \& Frega, F., Water Hammer in water distribution systems. Ital. J. Eng. Geol. Environ., 2018.

[21] Hall, J.W., Boyce, S.A., Wang, Y., Dawson, R.J., Tarantola, S. \& Saltelli, A., Sensitivity analysis for hydraulic models. Journal of Hydraulic Engineering. 2009.

[22] Baker, T. J., Mesh generation: Art or science? Progress in Aerospace Sciences. 2005.

[23] Tijsseling, A.S. \& Lavooij, C.S.W., Waterhammer with fluid-structure interaction. Appl. Sci. Res., 1990.

[24] Jaeger, C., Fluid transients in hydro-electric engineering practice, 1977.

[25] Jamshed S., Introduction to CFD. In Using HPC for Computational Fluid Dynamics, 2015.

[26] Fallis, A., Turbulence Modelling for CFD. J. Chem. Inf. Model., 2013.

[27] Al-Baali, A.G. \& Farid, M., Fundamentals of Computational Fluid Dynamics. In Food Engineering Series, 2006. 